\title{
DAS CONTADORAS DE HISTÓRIAS AO ESCRITOR DE LIVROS PARA A INFÂNCIA: NARRATIVAS DE TRADIÇÃO ORAL NA LITERATURA PARA CRIANÇAS BRASILEIRAS NA PRIMEIRA REPÚBLICA
}

\section{FROM STORYTELLERS TO THE CHILDREN'S BOOK WRITER: ORAL TRADITIONAL NARRATIVES IN BRAZILIAN CHILDREN'S LITERATURE DURING THE FIRST REPUBLIC}

\author{
Maria das Dores Soares Maziero ${ }^{1}$
}

\begin{abstract}
Resumo
O texto apresenta o início da publicação de narrativas de tradição oral no Brasil (contos de fadas e outros) em obras destinadas ao público infantil. Discute-se a transposição de histórias que sempre circularam na oralidade para a forma escrita, em um processo que, de certo modo, tira de cena a figura da contadora de histórias e a substitui pela do escritor/adaptador, contribuindo assim para a formação de um público leitor infantil, que passa a ter contato com as narrativas tradicionais através do livro impresso, e não mais apenas por práticas ligadas à oralidade. $\mathrm{O}$ artigo busca inventariar a presença de narrativas da tradição oral na literatura destinada às crianças brasileiras do final do século XIX e início do XX, bem como as estratégias utilizadas pelos escritores e editores para adaptar sua produção a uma sociedade que, a despeito de suas raízes rurais, confere à escrita um lugar de destaque. As fontes utilizadas são uma edição de 1898 de Histórias de Fadas, de Figueiredo Pimentel, e 28 exemplares da coleção Biblioteca Infantil Melhoramentos, publicados entre 1915 e 1925, sob a coordenação do Professor Arnaldo de Oliveira Barreto. A perspectiva teórica adotada contempla contribuições de L. Arroyo, M. Lajolo e R. Zilberman.
\end{abstract}

Palavras-chave: Literatura infantil; Adaptação de obras para a infância; Livro infantil.

\begin{abstract}
The text presents the beginning of oral tradition narratives' publication in Brazil (fairy tales and others) destined to the infantile public. We discuss the transposition of stories that have always circulated in orality to the written form, in a process that, in a way, takes the scene the storyteller and replaces it with the writer / adapter, thus contributing to the formation of a children's reading public, who comes into contact with the traditional narratives through the printed book, and no longer only for practices linked to orality. The article seeks listing the oral tradition narratives presence in the literature destined to Brazilian children of the late nineteenth and early twentieth centuries, as well as the strategies used by writers and editors to adapt their production to a society that, despite its rural roots, gives writing a prominent place. The sources used are an 1898 edition of Fairy Tales, by Figueiredo Pimentel, and 28
\end{abstract}

\footnotetext{
${ }^{1}$ Faculdade de Paulínia - FACP-Paulinia, SP, Brasil - Email: s.maziero@uol.com.br
} 


\section{OO DEVIR EDUCAÇÃO}

ISSN: 2526-849X

copies of the Biblioteca Infantil Melhoramentos collection, published between 1915 and 1925, under the coordination of Professor Arnaldo de Oliveira Barreto. The theoretical perspective adopted includes contributions from L. Arroyo, M. Lajolo and R. Zilberman.

Key-words: Children's literature; Adapting childhood's books; Children's books.

\section{Introdução}

Muito antes da invenção da escrita, homens e mulheres certamente já contavam histórias. As cavernas habitadas ou frequentadas pelos primeiros seres humanos, em diferentes partes do mundo, estão repletas de pinturas representando animais, pessoas e situações que narram fatos e cenas acontecidos há milhares de anos, e se não somos capazes de recuperar completamente as histórias que contam, é porque as vozes que as criaram também silenciaram há muito tempo.

$\mathrm{Na}$ Grécia antiga, também ainda antes de a escrita ter sido criada, as aventuras incríveis de heróis como Aquiles e Odisseu já eram cantadas pelos aedos e, assim, transmitidas geração após geração. A Ilíada e a Odisseia, obras que estão na gênese da literatura ocidental, tiveram sua origem na oralidade e foram assim conservadas por séculos, até terem sua forma escrita estabelecida por volta de 600 a.C.

A literatura infantil - denominação dada a uma vasta produção escrita destinada à infância - também trilhou caminho semelhante, tendo suas origens na literatura oral, da qual fazem parte as histórias contadas por homens e mulheres que viveram no campo ao longo dos séculos. Segundo Arroyo (1988, p. 29), "vieram elas também, as fontes [da literatura infantil ocidental] através da expressão oral, espraiando-se pelos povos da Europa, sofrendo em cada região uma acomodação bem acentuada". Já Coelho (1991, p. 13) afirma que "com relação à gênese da Literatura Popular/infantil ocidental, sabe-se que está naquelas longínquas narrativas primordiais, cujas origens remontam a fontes orientais bastante heterogêneas e cuja difusão, no ocidente europeu, se deu durante a Idade Média, através da transmissão oral”.

Posteriormente, a partir do final do século XVII, as histórias contadas por tantas camponesas e camponeses teriam ido parar nas páginas de obras de autoria de escritores circunspectos, que assumiram o papel de aprisionar palavras até então apenas faladas, em linhas e parágrafos de livros impressos. Conforme Darnton (1986, p. 30), “a maioria dos contos do repertório francês foi recolhida por escrito entre 1870 e 1914, durante 'a Idade de 


\section{Q DEVIR EDUCAÇÃO}

ISSN: 2526-849X

Ouro da pesquisa dos contos populares na França' e quem narrou as histórias foram camponeses que as haviam aprendido na infância, muito antes de a alfabetização se disseminar no campo".

No universo da literatura infantil, em especial, a "literatização" dessa produção oral iniciou-se em 1697, quando foi publicada em Paris a obra Contes de ma mére L'Oye, ou Contos da Mamãe Gansa, de Charles Perrault, livro composto por histórias da tradição oral recolhidas da cultura camponesa, adaptadas de modo a atender ao gosto de uma audiência mais sofisticada, que frequentava os salões da corte do rei Luís XIV (DARNTON, 1986). Lajolo corrobora essa visão, ao afirmar que a Europa "desde 1697 fazia circular entre a criançada Charles Perrault e seus confrades, que fundaram o gênero [Literatura Infantil] e instituíram o modelo" (LAJOLO, 1986, p. 44).

Um resquício da origem oral destes contos, no entanto, pode ser vista no frontispício da $1^{\text {a }}$ edição de Contes de ma mére L'Oye, que estampa a figura de uma mulher, aparentemente de origem camponesa - a julgar pelo avental e pelas roupas que veste - a qual conta histórias para três crianças que a circundam.

Seguindo a vertente de passar para a forma escrita as narrativas de tradição oral, no século XIX, na Alemanha, os irmãos Grimm publicam os seus Contos da criança e do lar (1812), também resultado da coleta de narrativas preservadas na memória de camponeses alemães. No entanto, segundo aponta Lyons (2011, p. 152), “embora a coleção dos irmãos Grimm tenha sido acolhida com entusiasmo, em um espírito de nacionalismo alemão, ela devia muito a precedentes franceses", já que, segundo este mesmo autor, muitos dos informantes dos Grimm teriam sido influenciados pelos contos de fadas publicados por Charles Perrault no século XVII.

Partindo desses pressupostos, este texto apresenta o início da publicação de narrativas de tradição oral no Brasil (contos de fadas e outros) em obras destinadas ao público infantil. Discute-se a transposição de histórias que sempre circularam na oralidade para a forma escrita, em um processo que, de certo modo, tira de cena a figura da contadora de histórias e a substitui pela do escritor/adaptador, contribuindo assim para a formação de um público leitor infantil, que passa a ter contato com as narrativas tradicionais através do livro impresso, e não mais apenas por práticas ligadas à oralidade. O artigo busca inventariar a presença de narrativas da tradição oral na literatura destinada às crianças brasileiras do final do século XIX e início do XX, bem como as estratégias utilizadas pelos escritores e editores para 


\section{OO DEVIR EDUCAÇÃO}

ISSN: 2526-849X

adaptar sua produção a uma sociedade que confere à escrita um lugar de destaque. As fontes utilizadas são uma edição de 1898 de Histórias de Fadas, de Figueiredo Pimentel, e 28 exemplares da coleção Biblioteca Infantil Melhoramentos, publicados entre 1915 e 1925, sob a coordenação do Professor Arnaldo de Oliveira Barreto.

\section{O surgimento da literatura infantil no Brasil}

No Brasil, como na Europa, a literatura oral precedeu a fundação de uma literatura infantil propriamente dita. Segundo Arroyo,

o menino colonial, do ponto de vista da literatura oral, contava com muitas estórias, mercê dessa interação oral que encontrava no Brasil, pela confluência das três correntes culturais assinaladas, condições de pleno desenvolvimento. Mas não apenas o menino da região do Nordeste - a área mais definida culturalmente no período colonial - mas também o menino do interior de Minas Gerais, dos Estados do Sul. (ARROYO, 1988, p. 46).

Ainda segundo Arroyo (1988), é possível perceber a importância do papel que exerceram velhos contadores e contadoras na infância de alguns escritores brasileiros nascidos no século XIX, através dos livros de memórias que estes escreveram. É o caso do sociólogo, ensaísta e historiador Gilberto Freire (1900-1987), do escritor e imortal Gilberto Amado (1887-1969), ou da memorialista Maria Madalena Antunes Pereira (1880-1959). Leonardo Arroyo afirma que aqueles homens e mulheres anônimos, cuja imagem ficou registrada na obra de tantos escritores, eram predominantemente descendentes de escravos, sendo “conhecidos simplesmente como 'contadores de estórias', quando deveriam ser designados pelos nomes africanos de akpalôs, ologbos, griotes, dialis como deveria ser" (ARROYO, 1988, p. 54), pois eram continuadores de uma tradição própria do continente africano.

Desses tantos escritores, destacaremos dois: José Lins do Rego Cavalcanti (19011957, Pilar/PB) e Manuel Viriato Corrêa B. Filho (1884-1967), que homenagearam em suas obras a contadora de histórias, de forma particularmente carinhosa e indicativa da importância dessa figura na infância deles e de tantos outros meninos nascidos no final do século XIX e início do XX.

O primeiro deles, José Lins do Rego, dedica algumas páginas de sua obra memorialística Menino de Engenho, publicada pela primeira vez em 1932, a descrever com 


\section{Q DEVIR EDUCAÇÃO}

ISSN: 2526-849X

carinho a figura da Velha Totonha ${ }^{2}$, "que vivia de contar histórias de Trancoso" (REGO, 1989, p. 49) e que aparecia de vez em quando no engenho do avô do autor, trazendo grande alegria para a meninada, que aguardava ansiosa pelas histórias maravilhosas que só ela sabia contar.

A Velha Totonha era "pequenina e toda engelhada, tão leve que uma ventania poderia carregá-la, andava léguas e léguas, a pé, de engenho a engenho, como uma edição viva das Mil e uma Noites" (REGO, 1989, p. 49). José Lins do Rego descreve suas qualidades: repertório de histórias amplo e variado, memória prodigiosa, voz capaz de interpretar a índole e a emoção das mais diferentes personagens, e a capacidade de pôr "cor local [...] nos seus descritivos" (REGO, 1989, p. 51), ou seja, a capacidade de adaptar personagens europeus à realidade das crianças que a ouviam. Assim, o Barba Azul da Velha Totonha era um senhor de Engenho de Pernambuco, e os rios e florestas que apareciam em suas histórias eram aqueles com os quais as crianças estavam familiarizadas.

Tanto essa velha contadora de histórias impressionou o menino José Lins do Rego que, em 1936, já adulto e escritor consagrado, ele publicou sua única obra destinada ao público infantojuvenil: o livro Histórias da Velha Totônia, no qual reconta quatro das histórias que ouvira daquela que tanta alegria e encantamento trouxe à sua infância.

Já Vovó Candinha tornou mais mágica a infância do escritor Viriato Corrêa (18841967, Pirapemas/MA), que a imortalizou na obra Cazuza, publicada pela primeira vez em 1938. Tratava-se de uma mulher de cerca de setenta anos, que ao visitar a filha que morava em Pirapemas/MA, fazia a alegria de Cazuza e das outras crianças do lugar, por ser "um ser à parte, quase sobrenatural, que se não confundia com as outras criaturas. É que ninguém no mundo contava melhor histórias de fadas do que ela" (CORRÊA, 2002, p. 24).

No Brasil, algumas das histórias que habitavam a memória da Velha Totônia e de Vovó Candinha já haviam ido para o suporte escrito em 1885, quando foi publicada, em Portugal, a $1^{\text {a }}$ edição de Contos populares do Brasil, do escritor Sílvio Romero, trazendo contos populares, segundo o próprio autor, "recolhidos por nós diretamente da tradição oral", seguindo a palavra "fielmente apanhada da boca do povo" (ROMERO, 1957, p. 441). Esta obra, no entanto, não foi lançada como literatura para a infância, mas sim como parte dos estudos de Sílvio Romero sobre o folclore brasileiro.

\footnotetext{
${ }^{2}$ Na edição de Menino de Engenho consultada (44. ed., 1989), aparece a grafia "Totonha", mas tal grafia é alterada para "Totônia" no título da obra Histórias da Velha Totônia. Sendo assim, apenas quando se tratar de referências à obra Menino de Engenho, usaremos a grafia registrada na edição consultada: "Totonha".
}

Revista Devir Educação, Lavras, vol.2, n.1, p.68-82, jan./jun., 2018. 
A Velha Totônia, de José Lins do Rego, e a Vovó Candinha, imortalizada por Viriato Corrêa, são representantes de uma geração de contadoras de histórias que ao longo do tempo preservaram, através da oralidade, histórias do campo do maravilhoso, graças a suas performances, memória prodigiosa e fórmulas próprias do contar, que povoaram de príncipes, princesas, fadas, seres encantados e objetos mágicos a imaginação de tantos meninos e meninas brasileiros.

No entanto, as crianças brasileiras pertencentes à classe socialmente privilegiada da segunda metade do século XIX e das décadas iniciais do século XX, além do acesso às histórias da tradição oral contadas por contadoras, amas e avós, também passaram a ter acesso a esse tipo de narrativa através de obras publicadas em Portugal e em países como França e Inglaterra, uma vez que era grande o número de preceptoras alemãs e francesas a quem era confiada a educação dos filhos da elite letrada deste período histórico.

Apenas em1894 a Livraria Quaresma lançou o livro Contos da Carochinha, obra que inauguraria a Biblioteca Infantil Quaresma, trazendo histórias de tradição oral recontadas por Figueiredo Pimentel. A obra trazia histórias de Charles Perrault, dos Irmãos Grimm, das Mil e uma noites e do folclore brasileiro. Assim, em termos de obra publicada no Brasil, adaptada por um autor nacional, estava "oficializada" a transposição de muitos dos contos preservados pela tradição oral para a forma escrita.

\section{Figueiredo Pimentel, adaptador de obras infantis}

Alberto Figueiredo Pimentel (1869-1914) foi um jornalista e cronista carioca que recebeu de Pedro da Silva Quaresma, proprietário da Livraria Quaresma, a incumbência de adaptar para a infância brasileira histórias já contadas às crianças de outras partes do mundo por outros autores. À frente da Biblioteca Infantil Quaresma, Figueiredo Pimentel pode ser considerado um dos pioneiros no campo da literatura para a infância no Brasil, pois foi o primeiro a traduzir em linguagem acessível às crianças brasileiras os contos maravilhosos que circulavam no Brasil do século XIX, em traduções portuguesas ou textos franceses ${ }^{3}$.

A obra de Figueiredo Pimentel escolhida neste trabalho para indicar alguns dos passos seguidos por escritores para adaptar as histórias da tradição oral para a forma escrita, no

\footnotetext{
${ }^{3}$ Sobre o trabalho de Figueiredo Pimentel como adaptador da obra Contos da Carochinha, ver:

MAZIERO, Maria das Dores S. Alberto Figueiredo Pimentel adaptador de obras infantis: quantos pontos aumenta quem conta um conto? Anais do IV Congresso Internacional de Literatura Infantil e Juvenil "Celebrando a Leitura", setembro de 2015.
}

Revista Devir Educação, Lavras, vol.2, n.1, p.68-82, jan./jun., 2018. 


\section{OO DEVIR EDUCAÇÃO}

ISSN: 2526-849X

entanto, não foi publicada pela Livraria Quaresma, mas sim pela J.G. de Azevedo/Francisco Alves \& Cia. Trata-se de um livro editado em Paris pela primeira vez em 1896. O exemplar utilizado para consulta é uma edição de 1898, adquirido em um sebo de Belo Horizonte.

Trata-se do livro Histórias de Fadas, que traz 20 histórias, distribuídas ao longo de 213 páginas, uma edição que pode ser considerada de luxo, pois tem capa dura revestida por um tecido chamado percalina e inscrições em dourado. A dedicatória presente na página de rosto do exemplar consultado indica que ele pertenceu a uma criança chamada Aracy, que o recebeu como prêmio em 31/03/1914, "pela sua applicação e procedimento"4.

As histórias trazidas pelo livro pertencem a autores como Charles Perrault (nove contos), Irmãos Grimm (uma), Hans C. Andersen (cinco) e Madame D’Aulnoy (duas), não tendo sido possível identificar a autoria de três dos contos. Apesar de ser possível identificar a autoria das histórias pelo título delas ("As fadas", "A bela adormecida no bosque", "O chapéosinho 5 vermelho", "A gata borralheira"), não é mencionado o nome de nenhum dos autores, figurando apenas o de Figueiredo Pimentel como responsável pela obra.

\section{Arnaldo de Oliveira Barreto e a coleção Biblioteca Infantil Melhoramentos ${ }^{6}$}

Outro escritor que também contribuiu para a constituição de um acervo de livros que incorporou histórias da tradição oral a obras para a infância brasileira foi o professor paulista Arnaldo de Oliveira Barreto (1869-1925), diplomado pela Escola Normal de São Paulo, Inspetor de Ensino e autor de cartilhas e livros escolares, como a Cartilha Analítica e a série de livros de leitura seriada Puiggari Barreto.

Convidado pela Weiszflog Irmãos (posteriormente Editora Melhoramentos) para organizar o lançamento de obras de literatura não didática destinada à infância brasileira, Barreto idealizou a Biblioteca Infantil Melhoramentos, série composta por livrinhos diferentes dos que então circulavam no país: eram de formato pequeno $(16,5 \mathrm{~cm}$ x 11,5 cm), com ilustrações coloridas e publicados de modo sistematizado, em volumes numerados em sequência (MAZIERO, 2015).

\footnotetext{
${ }^{4}$ Transcrição de parte da dedicatória, respeitando-se a grafia da época.

${ }^{5}$ Respeitou-se a grafia da época em que a obra foi publicada.

${ }^{6}$ Sobre a Biblioteca Infantil e Arnaldo Barreto, ver: MAZIERO, Maria das Dores S. Arnaldo Barreto e a Biblioteca Infantil Melhoramentos (1915-1925): histórias de ternura para mãos pequeninas. Tese de Doutorado defendida junto à FE/Unicamp, em 2015, sob orientação da Profa. Norma S. de Almeida Ferreira
}

Revista Devir Educação, Lavras, vol.2, n.1, p.68-82, jan./jun., 2018. 


\section{DEVIR EDUCAÇÃO}

ISSN: 2526-849X

O primeiro livro da coleção, O patinho feio, foi lançado em 1915. Trata-se de uma adaptação do conto homônimo de Hans C. Andersen, seguido de outras duas obras: $O$ soldadinho de chumbo, deste mesmo autor, e de $O$ velocino de ouro - da mitologia grega, em dois volumes.

A coleção ficaria sob a direção e coordenação de Arnaldo Barreto - que exercia simultaneamente as funções de autor/adaptador, editor e responsável pelos aspectos gráficos até 1925, ano em que faleceu. Durante o período em que Barreto coordenou a Biblioteca Infantil, foram publicados os 28 primeiros livrinhos da coleção, ditos "da primeira fase" (MAZIERO, 2015). Após o falecimento de Arnaldo Barreto, a coleção passou a ser coordenada por outro professor: Lourenço Filho, sob cuja direção continuou a ser publicada, tendo alcançado o número 100 em 1958, data em que foi encerrado o lançamento de novos títulos.

Os livros da $1^{\mathrm{a}}$ fase da coleção (1915-1925), publicados sob a direção de Arnaldo Barreto, trazem também algumas histórias de Charles Perrault, dos Irmãos Grimm e da Condessa d'Aulnoy, como já havia feito Figueiredo Pimentel nas obras que adaptara para a Livraria Quaresma. Assim, são três histórias de Perrault, sete dos irmãos Grimm e quatro da Condessa d'Aulnoy, além de outras de Hans C. Andersen e do folclore brasileiro e de outros países.

A Biblioteca Infantil Melhoramentos, idealizada por Arnaldo de Oliveira Barreto, foi especialmente importante no cenário da formação da literatura infantil brasileira, pois

contribuiu para o processo, em curso no início do século XX, de formação de um grande público leitor, basicamente constituído por crianças que, por apreciar o gênero de histórias trazidas pela coleção, vai determinar a consolidação de um tipo específico de publicação. Assim, o conjunto de livros reunidos insere Arnaldo Barreto e a Biblioteca Infantil Melhoramentos como parte do processo de formação dos leitores infantis brasileiros, que havia começado com Figueiredo Pimentel, que continuaria com as crianças que leram os livrinhos coloridos e de formato pequeno da coleção Weiszflog/Melhoramentos. (MAZIERO, 2015, p. 93)

\section{Estratégias utilizadas pelos adaptadores/editores para conformar à escrita histórias de tradição oral}

Contadoras como a Velha Totônia (REGO, 1989) ou a Vovó Candinha (CORRÊA, 1989) ficaram marcadas na memória de seus ouvintes graças aos recursos de que dispunham para dar vida às histórias que narravam. No campo da oralidade, esses recursos compõem a 


\section{Q DEVIR EDUCAÇÃO}

ISSN: 2526-849X

performance do contador, e deles fazem parte o repertório, a entonação dada a cada trecho narrado, a capacidade de "representar" sentimentos, sensações e estados de espírito das diversas personagens, num exercício que se aproxima da dramatização.

Ao serem passadas para a forma escrita, as histórias de tradição oral necessariamente sofreram transformações, até mesmo porque do ponto de vista linguístico algumas liberdades concedidas à oralidade são vetadas quando se trata da forma escrita, especialmente se há a preocupação de se "formar" e orientar a criança - como é próprio das produções destinadas ao público infantil. Para Zilberman (1986, p. 20), a literatura infantil converte-se em um gênero "primordialmente social, com visíveis inclinações pedagógicas, o que quer dizer interessada na transmissão de modelos adultos".

É possível identificar dois grupos de estratégias utilizadas por Figueiredo Pimentel e por Arnaldo Barreto no que diz respeito ao modo como adaptaram histórias da tradição oral para o público infantil: 1) Estratégias ligadas ao projeto editorial e à materialidade das obras; 2) Estratégias textuais, utilizadas no estabelecimento do texto escrito.

O termo "estratégia" será utilizado no sentido que lhe atribui Roger Chartier (2001), isto é, procedimentos e intervenções textuais e editoriais que visam conformar determinado gênero a determinado público, pensadas no polo da produção pelos autores, adaptadores, ilustradores e editores.

Do ponto de vista das estratégias ligadas ao projeto editorial e à materialidade das obras, é possível observar em Histórias de Fadas (Figueiredo Pimentel) e nos livrinhos da $1^{\text {a }}$ fase da Biblioteca Infantil Melhoramentos (Arnaldo Barreto) pelo menos dois tipos de procedimentos:

1) O tamanho reduzido dos volumes, adequados ao manuseio pela própria criança: os livrinhos da Biblioteca Infantil Melhoramentos medem 11,5 cm x 16,5 cm, enquanto que o de Histórias de Fadas, da Livraria de J.G. de Azevedo/Francisco Alves, mede $12 \mathrm{~cm} \times 18 \mathrm{~cm}$.

2) Presença de ilustrações: tanto Histórias de Fadas quanto os volumes da Biblioteca Infantil Melhoramentos trazem ilustrações. No caso da obra de Figueiredo Pimentel, estas são feitas a bico de pena, em preto e branco, sendo que cada história traz ao menos uma ilustração. Como a obra foi impressa em Paris, é possível supor que estas ilustrações tenham sido escolhidas pelos próprios impressores, provavelmente a partir de material que já teria sido utilizado para ilustrar as mesmas histórias publicadas em francês.

Revista Devir Educação, Lavras, vol.2, n.1, p.68-82, jan./jun., 2018. 


\section{Q DEVIR EDUCAÇÃO}

ISSN: 2526-849X

No caso dos volumes da Biblioteca Infantil Melhoramentos, as ilustrações representam o ponto alto da obra: muitas delas são coloridas e tecnicamente muito bem executadas, tendo sido feitas exclusivamente para a coleção pelo pintor e desenhista tcheco radicado no Brasil Franz Richter, apesar de não constar o nome do ilustrador em nenhum dos livrinhos da coleção.

Outro fator que deve ser mencionado em relação aos volumes da Biblioteca Infantil Melhoramentos é que todos os volumes da $1^{\text {a }}$ fase da coleção traziam uma capa (de autoria de F. Richter) que se tornaria característica: uma mulher mais velha (uma avó?) cercada por três crianças que parecem ouvi-la atentamente. Outra vez encontramos a figura da contadora de histórias, a exemplo do que já ocorrera com a capa da obra de Charles Perrault e da imagem presente nas recordações de José Lins do Rego, para quem a Velha Totônia estava "sempre com aquele seu sorriso de avó de gravura dos livros de histórias” (REGO, 1989, p. 54).

Em se tratando de obras para crianças, as ilustrações são muito importantes, na medida em que concretizam em imagens partes significativas do enredo. Pode-se pensar que suscitem parte do encantamento que as contadoras de antigamente provocavam em seus ouvintes apenas com palavras, gestos e expressões faciais.

Quanto às estratégias textuais, pertencem àquele conjunto de dispositivos que visam ao controle do sentido a ser construído pelo leitor: os procedimentos de produção de textos; "são as senhas, explícitas ou implícitas, que um autor inscreve em sua obra a fim de produzir uma leitura correta dela, ou seja, aquela que estará de acordo com sua intenção" (CHARTIER, 2001, p. 96).

Figueiredo Pimentel e Arnaldo Barreto utilizaram basicamente a adaptação, a tradução livre e o reconto, que consistem em formas de transpor para o suporte escrito um texto que já foi publicado por outro autor, em outro idioma, visando atender a um outro público leitor.

No caso destes dois autores, eles escolheram contos de fadas de escritores europeus como Charles Perrault, Irmãos Grimm e Hans C. Andersen, seguindo passos que parecem se iniciar com a tradução livre e/ou o reconto das histórias primeiras, ou seja, eles se mantêm fiéis ao enredo dos textos que se (re)conhece como sendo daqueles autores europeus, aos quais provavelmente tiveram acesso através da leitura de traduções portuguesas ou até de versões que por aqui circulavam em francês, inglês e alemão. É bastante provável que tenham lido edições em francês, uma vez que este idioma fazia parte dos conhecimentos esperados de escritores e letrados brasileiros do período em que as obras foram publicadas.

Revista Devir Educação, Lavras, vol.2, n.1, p.68-82, jan./jun., 2018. 


\section{Q DEVIR EDUCAÇÃO}

ISSN: 2526-849X

Essa tradução livre comporta o uso de recursos diversos de adaptação, como a atribuição de nomes próprios às personagens das histórias, supressão de trechos, inserção de descrições e fatos secundários, além de reiteradamente enfatizar o valor da obediência aos mais velhos e da prática de boas ações.

Para exemplificar, ainda que brevemente, escolhemos o conto Chapeuzinho Vermelho, em cuja versão eternizada por Charles Perrault o lobo devora tanto a menina quanto a avó. Já na versão recontada pelos Irmãos Grimm no século XIX, o lobo é morto pelo caçador e Chapeuzinho e sua avó escapam ilesas, protagonizando o tão esperado final feliz.

As adaptações feitas por Figueiredo Pimentel e por Arnaldo Barreto parecem contemplar elementos tanto da versão de Perrault quanto da dos Grimm, acrescidas de algumas inovações propostas por eles próprios.

Assim, Arnaldo Barreto, já no início de sua narrativa, acrescenta elementos ao cenário, ao dizer que Chapelinho Vermelho morava "em uma casinha verde, junto ao bosque, com seus paes" (BARRETO, s/d, p. 29). No decorrer da história, a menina encontra o lobo na floresta, revela a ele onde a avó mora e, como resultado, este chega primeiro à cabana e devora a pobre senhora. O desfecho de Barreto, porém, é um pouco diferente: Chapelinho Vermelho escapa do lobo porque os lençóis da cama em que este se encontrava deitado enroscam-se nas pernas dele, dando tempo a ela de fugir e encontrar ajuda junto a um lenhador (e não caçador), que mata o lobo a machadadas.

Já Figueiredo Pimentel, além de dar à menina o nome de Marieta, ainda cria um fato novo: a avó, na verdade, era a "Fada dos Jasmins", que no final da história livra a netinha das garras do lobo graças a sua mágica varinha de condão e ainda a incentiva a escolher o castigo a ser dado ao malvado. A menina deixa a escolha do castigo a cargo da avó, que amarra busca-pés desde a ponta até o focinho do animal, dizendo: "vai, malvado, correndo por ahi fóra até que vás apagar o fogo no poço, onde morrerás afogado" (PIMENTEL, 1898, p. 166).

No que diz respeito ao final dado a ambas as narrativas, os autores enfatizam o tom moralizante do conto, ao registrarem que a menina aprendera a lição, deixando no passado a desobediência aos conselhos dados pelos mais velhos. Assim, Arnaldo Barreto relata que "o susto e a pena de ser causa da morte da avozinha levaram ao leito Chapelinho Vermelho [que] quando se restabeleceu, mudou inteiramente de proceder: attendeu sempre aos conselhos de seus paes, e tornou-se dócil, submissa e obediente" (BARRETO, s/d, p. 36).

\footnotetext{
${ }^{7}$ Respeitou-se a grafia da época em que a obra foi publicada.

${ }^{8}$ Respeitou-se a grafia da época em que a obra foi publicada.
}

Revista Devir Educação, Lavras, vol.2, n.1, p.68-82, jan./jun., 2018. 


\section{OO DEVIR EDUCAÇÃO}

ISSN: 2526-849X

Já Figueiredo Pimentel é mais enfático ao falar do arrependimento da menina:

Depois d'isto [o castigo do lobo] disse a Fada para Chapéosinho Vermelho: "Has de prometter que de hoje em diante, quando tua mãi te mandar a algum recado, não te has de demorar pelo caminho, nem conversar com quem não conheces, dizendo-lhe o que vais a fazer; e si assim fizeres, dou-te por dom que serás mui formosa e casarás com um fidalgo."

E assim foi. Crescendo, Chapéosinho Vermelho fez-se tão discreta e tão formosa, que foi pedida em casamento por um grande fidalgo da visinhança, com o qual casou e viveu muito feliz. (PIMENTEL, 1898, p. 165-166)

O uso desses recursos sinaliza a preocupação dos autores no sentido de atingir o público leitor pretendido pelas obras: crianças em idade escolar, que os autores imaginavam que apreciassem a linguagem simples, direta, e que gostassem de encontrar no texto lido referências a elementos com os quais estavam familiarizadas, quase como se fosse uma tentativa de dar uma "cor local aos seus descritivos" (REGO, 1989, p. 51), como faziam contadoras como a Velha Totônia.

Também é necessário destacar o que já foi apontado por muitos pesquisadores a respeito do caráter moralizador das primeiras produções destinadas ao público infantil, refletindo a preocupação dos adultos com a inculcação de valores e de comportamentos modelares esperados das crianças. A respeito das primeiras obras destinadas à infância, Zilberman (1986, p. 18) afirma que "a literatura infantil transformou-se num instrumento que, aliado à pedagogia nascente, procurou converter cada menino no ente modelar e útil ao funcionamento da engrenagem social".

\section{Considerações finais}

Os livros analisados podem ser relacionados a duas esferas diferentes: a primeira à da literatura para crianças no Brasil, que teve como ponto de partida a tradução, adaptação e reconto de narrativas tradicionais; a segunda, à da constituição e desenvolvimento do mercado editorial voltado para a produção de livros infantis.

Juntamente com as obras contendo adaptações feitas por Figueiredo Pimentel, a Biblioteca Infantil Melhoramentos foi responsável pelo processo de nacionalização da literatura infantil brasileira, tendo participado da "fase de estruturação do gênero" (LAJOLO E ZILBERMAN, 1987).

Revista Devir Educação, Lavras, vol.2, n.1, p.68-82, jan./jun., 2018. 


\section{Q DEVIR EDUCAÇÃO}

ISSN: 2526-849X

Deste modo, o trabalho desenvolvido por Figueiredo Pimentel o torna pioneiro no campo da nacionalização da literatura infantil brasileira, contribuindo para o início da formação de um público leitor.

Já a Biblioteca Infantil Melhoramentos, idealizada por Arnaldo Barreto, representa o lançamento de um projeto editorial especial: formato reduzido dos volumes, quantidade de histórias trazidas em cada um, ilustrações coloridas feitas por um único pintor. Uma diferença no polo da produção, entretanto, deve ser apontada neste caso: Arnaldo Barreto parece ter tido autonomia para cuidar da execução do projeto que idealizou durante todas as etapas: era o adaptador dos textos, o editor, e quem controlava aspectos técnicos como diagramação, formato e qualidade estética das ilustrações.

Para Arroyo (1988), a Biblioteca Infantil Melhoramentos foi "a mais popular coleção de livros para crianças, como também a única em extensão e seleção de leitura".

Há um significativo sucesso editorial alcançado: Na história da Literatura Infantil é dado destaque para a surpreendente tiragem de 50.500 exemplares para A menina do narizinho arrebitado de Monteiro Lobato, em 1921. Os três primeiros números da coleção Biblioteca Infantil Melhoramentos, em 1915, tiveram uma tiragem total de 140.000 exemplares, sendo 40.000 para $O$ patinho feio, 40.000 para $O$ soldadinho de chumbo e 30.000 para cada uma das duas partes de $O$ velocino de ouro (MAZIERO, 2015).

José Lins do Rego inicia sua obra Histórias da Velha Totônia com um texto intitulado "Aos meninos do Brasil", no qual apresenta a figura da contadora de histórias de sua infância, descrita como uma "boa velhinha, de voz tão mansa e de vontade tão fraca aos pedidos dos seus ouvintes" (REGO, 1997, p. ix), para em seguida lamentar o fato de que "todas as velhas Totônias do Brasil se acabaram, se foram. E outras não vieram para o seu lugar. Este livro escrevi pensando nelas..." (REGO, 1997, p. ix). Ao mesmo tempo, o escritor deixa registrado seu propósito ao escrever o livro: tentar transmitir aos meninos brasileiros a ansiedade e o prazer com que ele próprio escutava as histórias contadas pela velha contadora.

A literatura infantil está ligada, indiscutivelmente, à tradição oral, mesmo que as histórias tenham migrado da boca dos velhos contadores para as páginas dos livros. Na ponta inicial dessa linha, sempre em movimento, estão os contadores populares: akpalôs, ologbôs, dialis ou griotes, como quer Leonardo Arroyo (1988), seguidos por escritores como Charles Perrault, Figueiredo Pimentel ou Arnaldo Barreto, que passaram as histórias para o suporte escrito, mas também pelo adulto que lê ou (re)conta essas histórias para as crianças, 


\section{DEVIR EDUCAÇÃO}

ISSN: 2526-849X

especialmente o professor, esse moderno contador dessas e de tantas outras histórias eternas, porque capazes de sempre fazer renascer a magia que as inspirou.

\section{Referências}

ARROYO, Leonardo. Literatura Infantil Brasileira. São Paulo: Melhoramentos, 1988.

CHARTIER, Roger. Do livro à leitura. In: CHARTIER, R. (dir.). Práticas da leitura. Trad. Cristiane Nascimento; introd. de Alcir Pécora. 2.ed. São Paulo: Estação Liberdade, 2001.

COELHO, Nelly Novaes Dicionário Crítico de Literatura Infantil e Juvenil Brasileira: Séculos XIX e XX. São Paulo: Editora da Universidade de São Paulo, 1995. Panorama histórico da literatura infantil/juvenil. São Paulo: Ática, 1991.

CORRÊA, Viriato. Cazuza. 40. ed. São Paulo: Companhia Editora Nacional, 2002.

DARNTON, Robert. Histórias que os camponeses contam: O Significado de Mamãe Ganso. O grande massacre de gatos, e outros episódios da história cultural francesa; trad. de Sonia Coutinho. Rio de Janeiro: Graal, 1986.

LAJOLO, Marisa. Circulação e consumo do livro infantil brasileiro: um percurso marcado. In: KHÉDE, Sônia S. (org.). Literatura Infanto-juvenil: um gênero polêmico. Porto Alegre: Mercado Aberto, 1986.

LAJOLO, Marisa. e ZILBERMAN, Regina. Literatura Infantil Brasileira - História \& Histórias. São Paulo: Ática, 1987.

LYONS, Martyn. Livro: uma história viva; trad. Luís Carlos Borges. São Paulo: Editora Senac, 2011.

MAZIERO, Maria das Dores Soares. Arnaldo Barreto e a Biblioteca Infantil Melhoramentos (1915-1925): histórias de ternura para mãos pequeninas. Campinas, SP:[s.n], 2015. Tese de Doutorado, FE/Unicamp.

REGO, José Lins do. Menino de engenho. 44. ed. Rio de Janeiro: José Olympio, 1989.

Histórias da Velha Totônia. 10. ed. Rio de Janeiro: José Olympio, 1997.

ROMERO, Silvio. Contos populares do Brasil. Rio de Janeiro: José Olympio Editora, 1954.

ZILBERMAN, Regina. O lugar do leitor na produção e recepção da literatura infantil. In: KHÉDE, S.S. (org.). Literatura Infanto-juvenil: um gênero polêmico. Porto Alegre: Mercado Aberto, 1986.

EXEMPLARES UTILIZADOS PARA ANÁLISE E/OU CONSULTA: 


\section{OO DEVIR EDUCAÇÃO}

ISSN: 2526-849X

PERRAUlT, Charles. Contos de Perrault. Belo Horizonte e Rio de Janeiro: Villa Rica Editoras Reunidas Ltda, 1994, $4^{\text {a }}$ edição.

A gata borralheira. Chapelinho Vermelho. As fadas. 2. ed. São Paulo: Comp. Melhoramentos de S. Paulo, Weiszflog Irmãos Incorporada. (Biblioteca Infantil, no 22).

PIMENTEL, Figueiredo. Histórias de Fadas. Livraria de J. G. de Azevedo, Editor. Rio de Janeiro, 1898. 